\title{
Precipitate Evolution In Zry-4 Oxidation
}

\author{
P.B.Bozzano, M. Ipohorski, R.A.Versaci \\ Departamento Materiales, Centro Atómico Constituyentes, Comisión Nacional de Energía \\ Atómica, Av. Gral. Paz 1499 (1650) San Martín, Buenos Aires, Argentina.
}

The microstructure of $\mathrm{Zr}$ alloys has been a subject of study during the last decades due to its influence on the manufacturing of fuel elements sheaths for power reactors. In particular, Zircaloy - 4 (\%wt Sn 1.45 - 1.5, Fe 0.18 - 0.24, Cr $0.07-0.13$, O 1400ppm, Zr to balance), is widely used as fuel cladding material.

Of all the alloying elements only $\mathrm{Sn}$ is in solid solution. For low temperatures $\left(\mathrm{T}<600^{\circ} \mathrm{C}\right) \mathrm{Fe}$ and $\mathrm{Cr}$ are present in the form of second phase particles. These intermetallic precipitates are about 10 - $1000 \mathrm{~nm}$ in diameter, depending on the fabrication conditions. The structure, composition, average size and morphology of the second phase precipitates are closely related to the corrosion behavior of Zry-4.

It is known that during the initial oxidation of zirconium alloys thin coherent oxide films of $\mathrm{ZrO}_{2}$ form over the whole surface, including the intermetallic particles lying on the surface. The precipitates are accommodated in the oxide film in a non- oxidized state, and then the zirconium present inside the precipitates is gradually oxidized to either cubic or tetragonal $\mathrm{ZrO}_{2}$. The precipitates in the oxide layer are subjected to a delayed oxidation as compared to the matrix, accompanied by the rejection of a significant proportion of their iron content. Previous works showed that precipitates undergo chemical composition changes after open furnace oxidation: EDS (Energy Dispersive Spectroscopy) showed the presence of $\mathrm{Zr}, \mathrm{Cr}$ and $\mathrm{Fe}$ within both nonoxidized and partially oxidized precipitates, but no $\mathrm{Fe}$ was detected within the oxidized ones. Then, it was suggested that a progressive $\mathrm{Fe}$ rejection towards the oxidized $\mathrm{Zr}(\mathrm{Cr}, \mathrm{Fe})_{2}$ precipitate / oxidized matrix frontier takes place.

In the present work, as- received commercial Zircaloy- 4 furnished by Teledyne Wah Chang was characterised by Analytical Electron Microscopy (AEM) techniques, before and after an oxidation treatment in open furnace at $650^{\circ} \mathrm{C}$. AEM analysis was carried out in a CM 200 Philips microscope with and EDAX- DX4 system operated at $160 \mathrm{kV}$.

Figure 1 shows a BF- TEM image of Zry-4 and of a non- oxidised precipitate with its corresponding EDS spectrum. The $\mathrm{Fe} / \mathrm{Cr}$ atomic ratio was found to be $\cong 1.5$. Inside the Zry-4 `s oxide layer non- oxidised precipitates (i.e. original intermetallic precipitates) with a nominal $\mathrm{Fe} /$ $\mathrm{Cr}$ ratio of 1.5 were found as well as oxidized precipitates with an $\mathrm{Fe} / \mathrm{Cr}$ ratio decreased to 0.5. (Figure 2). 

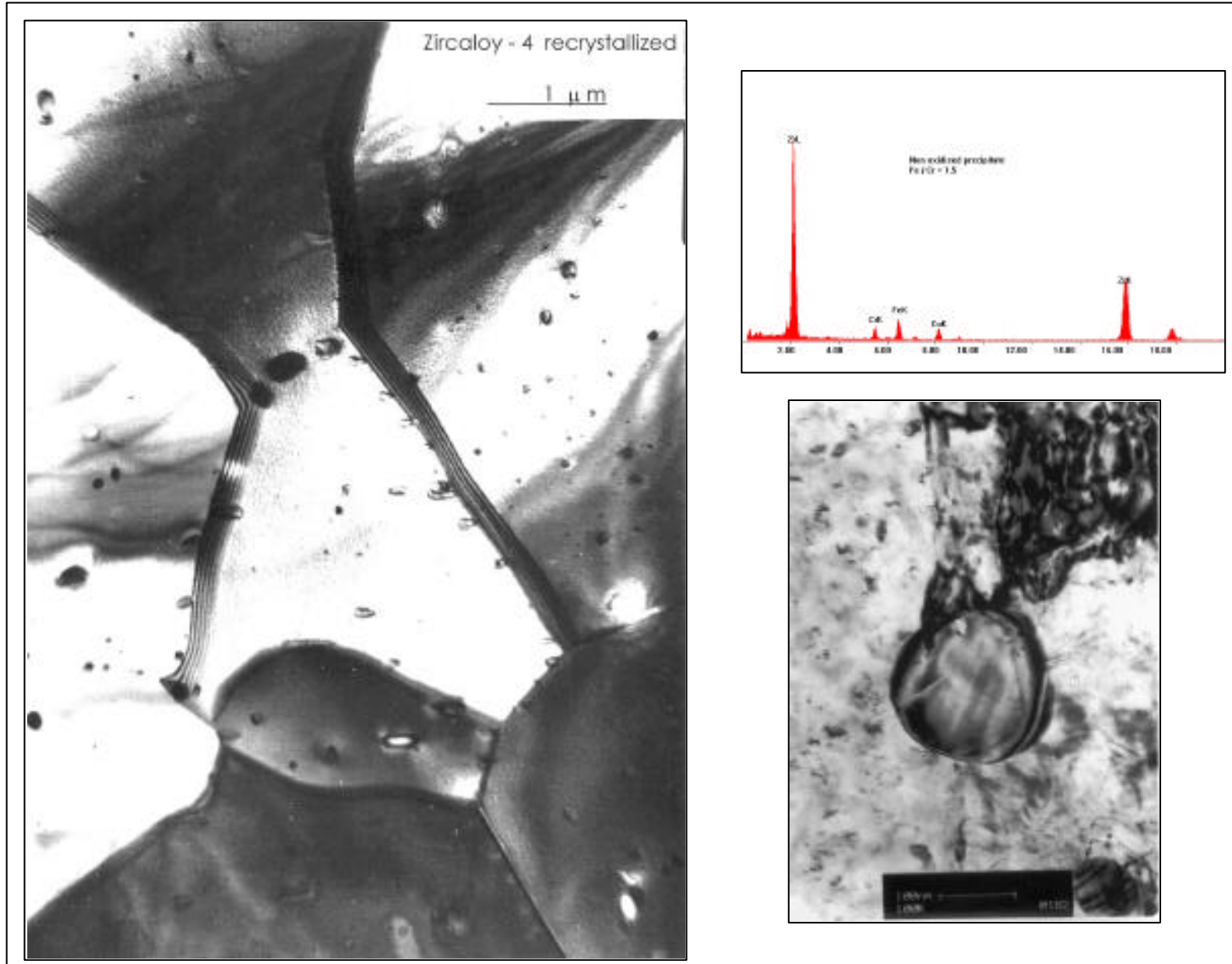

Figure 1 : BF- TEM image of non- oxidized Zry-4. The EDS spectrum corresponds to a precipitate with a $\mathrm{Fe} / \mathrm{Cr}$ atomic ratio $\cong 1.5$.

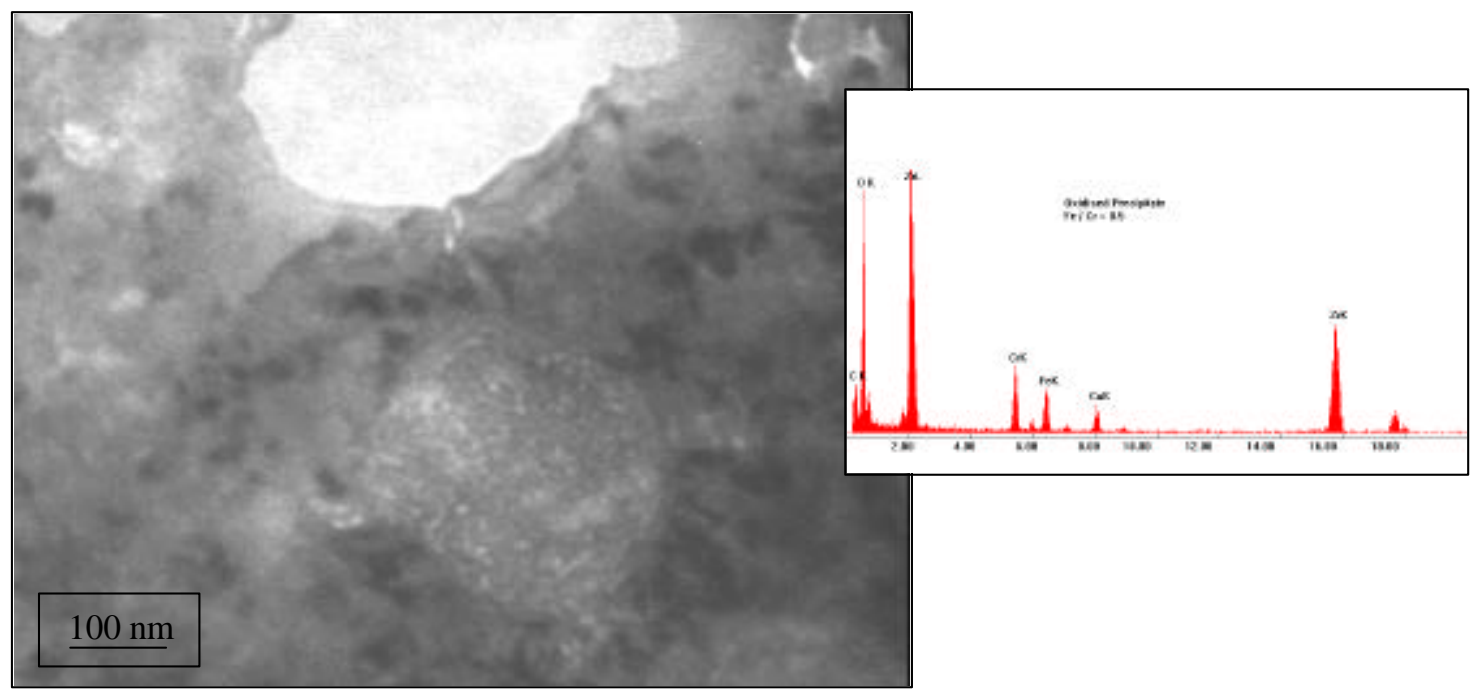

Figure 2: BF- TEM image of an oxidized precipitate and its corresponding EDS spectrum . The $\mathrm{Fe} / \mathrm{Cr}$ atomic ratio was found to be $\cong 0.5$. 